\title{
sobre Las lenguas vivas. Zonas de exilio y traducción en Manuel Puig, de Delfina Cabrera.
}

\author{
Buenos Aires: Prometeo Libros, 2016
}

GRACIELA GOLDCHLUK Universidad Nacional de La Plata - CONICET, Argentina / gracielagoldchluk@gmail.com

En el mar de bibliografía sobre Manuel Puig pocos libros están llamados a perdurar. No tengo ninguna duda de que Las lenguas vivas es uno de ellos, pero hay algo más: creo que es el primer libro nuevo sobre Puig, el primero que interpela una obra repetidamente señalada como singular desde un lugar diferente. Para comenzar, Cabrera no distingue entre novelas, cartas, manuscritos, guiones, proyectos; dibuja una zona y aclara que «hacer zona es el acto de delinear un espacio que no funcione como frontera sino que se aproxime a una orilla: sin límites fijos ni un comenzar o terminar fijos» (21); pero lo que interesa es lo que esta Stalker encuentra en su arrojar acá y allá líneas de lectura. A lo largo del libro nos vamos a encontrar con la puesta en evidencia de transformaciones invisibles que ocurren en rincones muy poco explorados de la escritura de Puig y que iluminan como destellos cualquier otro lugar donde, a partir de ahora, ejerzamos nuestra lectura.

\section{Capítulo 1: Los primeros guiones}

El lugar común afirma y se afirma al establecer una jerarquía de escrituras en las que la originalidad sería acaso el bien supremo. Ese razonamiento ubica a los guiones, como las cartas y la traducción, en el último escalón escritural, ya que no existen sin un referencial externo al que deben servir (la película, el corresponsal, el original). Por su parte, Puig comienza a (mal) escribir (mal) traduciendo guiones, pero acaso esa infidelidad, ese ruido, sea el motor de toda la escritura puigiana y lo que además la mantiene viva. Tal vez el comienzo no se trató simplemente de un error, un accidente ubicado en el tiempo que lo transportó desde ese no lugar a su casa, la literatura. Esta parece ser la posición desde donde lee Cabrera, el error como errancia y como única posibilidad de hacer o de ser, porque a Puig la voz le sale traduciendo, que es decir transformando. No se trata tampoco de ir desde la oralidad a la escritura. Como es evidente, no son sólo las voces sino que también las imágenes y los patrones mismos (de bordado, de dibujo, de género o de escritura) entran en transformación. Si la teoría literaria supo trabajar el texto como tejido, las escenas caribeñas bordadas que aparecen en Ball Cancelled, el primer guión de Puig, le sirven a esta autora para describir el modo en que el escritor desarma la jerarquía establecida en más de cien años de

\footnotetext{
Para citar este artículo: Goldchluk, Graciela (2018). «Sobre: Las lenguas vivas. Zonas de exilio y traducción en Manuel Puig, de Delfina Cabrera». El taco en la brea 7 (diciembre-mayo), 212-216 Santa Fe, Argentina: UNL. DOI: https://doi.org/10.14409/tb.voi7.7367
} 
teoría de la traducción que, dicho sea de paso, es una mirada del padre. Para decirlo en palabras de Cabrera: «Puig desata el nudo afectivo del monolingüismo y crea mediante la traducción un texto monstruoso que desestabiliza la pretensión ontológica de la idea de original» (46). Tanta precisión sólo puede alcanzarse con una lectura intensiva de la obra de Manuel Puig, que busque en las entrevistas con el mismo ahínco con que lee una novela, pero sobre todo que piense que algo hay ahí que es diferente y reclama ser leído no sólo en su diferencia sino especialmente en su propio diferimiento, en la precaria detención de un mundo que se hace presente como formas del suspenso en el cine. Este poder de la traducción, afirma Cabrera, es posible porque en el bordado de la literatura de Puig no se ven los hilos, nunca sabemos cuándo se pasa de una lengua a otra o cuándo habla el autor y cuándo los personajes, porque al contrario de lo que parecería no hay identidades estables (el niño, la loca, el ama de casa, el psicópata crítico de arte, el militante, la artista) así como no hay lengua. Los excluidos no forman una comunidad y por lo tanto para hablar están obligados, al igual que el escritor, a traducir, pero la traducción «no se basa en una relación original con la lengua, ni siquiera se ejecuta entre lenguas, sino entre jergas, idiomas, voces» (59). En un arco que va desde estos primeros guiones hasta una de las novelas más complejas como es Maldición eterna a quien lea estas páginas, Delfina Cabrera va leyendo las transformaciones allí donde la crítica leyó la mala traducción, la mala escritura, el mal dominio del inglés o del francés o del español, para recordarnos que ciertas escrituras son capaces de sacarle la lengua a la literatura.

\section{Capítulo 2: Ficciones nacionales}

En lugar de comenzar por el siglo XIX, este capítulo comienza con una selección de preguntas presentes en pruebas de inmigración del siglo XXI. La sola lectura de preguntas sobre la tortilla a la española junto con la exigencia de conocer el apellido Goethe o el orden de los santos nacionales nos impide imaginar el problema de la lengua y de la traducción como cuestiones meramente gramaticales. Si, como propone Glissant, «toda lengua es en sus orígenes una lengua créole», Cabrera afirma que «a través del análisis de la traducción en la literatura de Puig será posible repensar las categorías modernas mediante las cuales se han concebido la nación y la lengua nacional» (65). Este capítulo explora las discusiones más actuales en torno a la lengua nacional al tiempo que recupera las discusiones explícitas e implícitas que dominaron la literatura argentina, en las cuales Manuel Puig irrumpe de manera inconveniente. El peronismo parte el siglo por la mitad y Puig, que era amigo de Silvina Ocampo, despliega en su primer guión en español unos detalles que para la sensibilidad de la poeta pertenecían al orden de la pesadilla. Acá Cabrera habla de la representación de Evita que aparece en la figura de Nélida, personaje central de La tajada. Como al pasar, señala que Puig se ocupó de ella antes que Walsh, Perlongher o Copi, pero también que hay en esa composición un trabajo de montaje donde lo artificial se presenta como verdadero. La sinceridad del artificio marca una diferencia de clase y «tajea» la naturalidad esgrimida por los dueños de la lengua que tuvieron su expresión en la revista Sur. La escucha literaria señalada por Alberto Giordano, quien por primera vez advirtió que «Puig no escuchó la voz de algo sino algo en una voz» sólo pudo ser enunciada, comunicada, desde un lugar impropio. Es así, a partir del desplazamiento y la impropiedad que caracterizan la traducción, como Delfina Cabrera entiende el acercamiento de Manuel Puig a la novela, que le permitió «una forma de experimentación, artificial por definición, y marcada históricamente por la escritura de la memoria» (104). 


\section{Capítulo 3: El exilio desplazado}

Como corresponde a un libro que comienza poniendo en tela de juicio las categorías de literatura, lengua nacional, identidad y pueblo, un libro que diseña un aparato crítico llamado «zona de traducción» y aclara que «no hay una zona que preceda a una acción sobre el espacio» (21), la categoría de exilio es necesariamente puesta en duda en sus presupuestos identitarios, así como la noción de «extraterritorial» que, según advierte Cabrera, sigue teniendo a la nación y la lengua como referentes al tiempo que reafirma la imagen del intelectual como hombre blanco, burgués, heterosexual. En suma y para comenzar «El desplazamiento de Puig no es más o menos extraterritorial: directamente desplaza la categoría nostálgica y trágica de patria que ha fundado la comunidad política moderna» (109). El núcleo de este capítulo es la articulación entre exilio y revolución como gesto productor de una identidad regional latinoamericana. En este punto Cabrera rescata una entrevista a Manuel Puig de 1972, tomada de la compilación de Julia Romero y muy escasamente citada, donde el escritor afirma que la literatura «en este momento en que están pasando cosas, no mueve nada» y agrega que le gustaría «hacer periodismo de choque». En el contexto del caso Padilla, encarcelado en Cuba después de recibir el Premio Nacional de Poesía y con una declaración firmada por numerosos intelectuales entre los que se figuraban amigos entrañables como Cabrera Infante, Severo Sarduy y Luis Goytisolo, esta declaración le permite a Delfina Cabrera reflexionar sobre el problema de la autonomía del arte directamente ligada a problemas de representación. En las novelas de Puig, afirma Cabrera, el vínculo entre el Estado y los sujetos se juega en el terreno de lo decible, pero no en términos de censura sino de episteme: «Al poner en duda qué se entiende por espacio político, los espacios ficcionales de Puig permiten reflexionar acerca de los estereotipos políticos de una época» (132). En este punto me aparto del libro de Cabrera para pensar mi propio trayecto de investigación, específicamente mi sorpresa al comprobar que la crítica no había visto una Madre de Plaza de Mayo en el final de Pubis angelical, a pesar o precisamente porque no estaba metaforizada sino trasladada a un entorno futurista posapocalíptico. Estética realista suponía contenidos políticos, mientras que lenguaje de ciencia ficción con protagonista femenina no admitía tales contenidos. De haber existido Las lenguas vivas cuando escribí mi tesis hubiese tenido el camino allanado para hacerme entender, o para comprender mejor la disrupción Puig. Regresando al libro que nos ocupa, vemos que Cabrera establece un diálogo con el trabajo de Guillermina Rozenkrantz para pensar junto con ella la relación de los cuerpos con los espacios de exilio (enfermedad, sexualidad disidente, cárcel, renuncia a la maternidad) y amplía el diálogo crítico hasta la visión de América Latina en su literatura para encuadrar a Manuel Puig en operaciones de micropolítica que Jitrik lee en los modos de traducción y diálogo. Aunque en este caso no se lo nombre, Puig (ahora con Macedonio) siempre está, aparece por el costado de lo inefable.

\section{Capítulos 4 y 5: La intimidad del registro y una maldición, eterna...}

En los dos capítulos finales, que se abren con un epígrafe de César Aira, Cabrera exhibe su labor de lectora de manuscritos, una tarea tan poco frecuente como dada a confusiones. No se trata de descubrir aquí alguna verdad que explicaría ese grano de la voz único e irrepetible, sino que simplemente este estudio sobre Puig, sobre unas zonas que se van trazando a medida que se ejerce una lectura, echa mano de todo lo que tiene a su alcance, y por fortuna hay un archivo que contiene, además de textos publicados, reportajes, ensayos y películas, testimonios escritos de una actividad creadora. De este lado del archivo, como integrante del grupo que inició la tarea 
y encargada posteriormente de llevarla adelante hasta una descripción que se sueña completa y accesible, no me queda más que agradecer la fortuna de una lectura semejante. Aprendimos que el archivo no mira hacia el pasado sino como el ángel de la historia evocado por Benjamin, supimos que su tiempo gramatical es el futuro anterior, esperamos que en algún momento eso haya generado otras lecturas, haya mostrado las potencialidades de un tiempo por venir. Si hay una nueva era en la crítica literaria, como lo anunció Sarlo respecto de Saer y lo anuncia este libro respecto de Puig, es también por el archivo, ese dispositivo de lectura que permite, entre otras cosas, «hacer zona».

La lectura que hace Cabrera de El beso de la mujer araña sorprende por el acento puesto en el procedimiento como marca de género. Parece extraño, después de leerlo, que hasta ahora no se haya considerado que una novela que transcurre en una cárcel y juega todo el tiempo con el suspenso pertenezca por derecho propio al género policial. Dentro de ese género el maestro será Walsh, por el tipo de policial armado en base al montaje de documentos. No quiero desarrollar la argumentación de Cabrera, sino más bien develar la filiación de una crítica que elige una estirpe basada en la lectura fina y la mirada del detalle. Delfina Cabrera describe la novela como el artificio de una intimidad que llega hasta nosotros por la mano de la transcripción. Cada capa de la novela (diálogos, notas al pie, informes policiales, flujo de conciencia) da cuenta de una investigación taimada que es llevada a cabo para descubrir y al mismo tiempo ejecutar «el asesinato de la ficción identitaria central en el paradigma del humanismo» (165). En ese camino de lectura, la maestra es María Moreno, y como estamos en plan detectivesco reconocemos finalmente el nombre que el policial oculta, la estela en la que se deja llevar la escritura de Las lenguas vivas. En un deambular que ahora imaginamos acompañadas de Moreno, Cabrera vuelve a lo suyo y nos lleva a recorrer zonas de transcripción, de traducción, de pasajes y de interrupciones. En esta lectura tienen peso, entre otras consideraciones, el tamaño de los grabadores en 1978, la posibilidad o no de incorporar cursivas en la máquina de escribir, las notas que ya aparecían en novelas anteriores y las operaciones de traducción presentes en los primeros guiones. Un archivo es un entramado complejo que permite a esta crítica leer en Puig una anticipación de «las teorías que, años después, pensarán al sexo y al género no ya como naturales sino como aparatos inscriptos en un sistema tecnológico complejo» (175). Al mismo tiempo y desde el fondo de esos aparatos que lo son de producción y reproducción, una voz surge artificial, acusmática, sensible, asincrónica, mestiza, «para saber a distancia, en la noche, que estamos vivos» (Aira en su epígrafe, 145).

Y el libro arriba, así, al grande finale, es decir al lugar de la literatura de Puig donde efectivamente, exilio y traducción se unen: la escritura de Maldición eterna a quien lea estas páginas, novela escrita y ambientada en una Nueva York del desencanto, en una lengua por fin extranjera de modo identificable, con un personaje argentino, viejo, enfermo y exiliado político, elementos todos que hubieran cumplido su propósito reivindicativo en la pluma de casi cualquier escritor que no fuera Manuel Puig, especialmente cuando fue publicada en 1980, en pleno auge de la dictadura vernácula. Delfina Cabrera recorre brevemente estos atributos para señalar las perplejidades de la crítica frente a su no cumplimiento y se detiene en los modos que tiene la escritura de Puig de enunciar aquello que no puede ser nombrado, lo que aún no tiene palabras, lo que espera a ser audible en una voz. Para ello compara las dos versiones publicadas de la novela (en inglés y en español) y examina sus manuscritos, que incluyen páginas redactadas en francés, para señalar lo que no hay: «Puig no sacó las marcas de localización de la lengua, ni tampoco elabora un español 
o un inglés "neutro": las sucesivas reescrituras de las traducciones transforman el texto en algo inexistente puesto que ya no hay solidez de ninguna lengua sobre el texto» (214). En este capítulo se ponen en juego las teorías sobre la traducción que el libro fue desplegando con la maestría de quien se preocupa por dar a conocer las herramientas con las que trabaja. Como estamos en las últimas páginas vemos que hemos aprendido también algo sobre traducción, sobre lengua y sobre debates en torno a identidades, y que todo esto fue necesario para que volvamos a Puig y podamos mirarlo más de cerca, podamos leerlo hasta volver a escuchar, como quería Chartier a través de Quevedo, «a los muertos con los ojos». En este ejercicio de hacer audible eso que no es del orden de lo semántico sino de una cierta propiedad impropia de la voz, Cabrera encuentra la pregunta que formula el personaje norteamericano de la novela: «la de Larry es la pregunta por el privilegio que ha tenido la palabra escrita en occidente y por las disputas políticas en torno a la propiedad de esa palabra» (216), y esa pregunta que atraviesa toda la literatura de Puig y más allá (es decir toda su escritura) reza, en la página 53 de la novela: «De todos modos, ¿a quién mierda le va a interesar lo que hablemos nosotros?».

Quisiera para finalizar regresar a lo que hay de nuevo en Las lenguas vivas. Por un lado, el libro se pregunta por qué gran parte de la crítica, que ha señalado repetidamente cómo Puig pone en cuestión la división entre cultura alta y baja junto con otra serie de oposiciones binarias, se ha afirmado sin embargo en la lectura en clave literaria de algunas novelas dejando de lado la gran masa escritural que ya era evidente aún antes de que sus manuscritos fueran accesibles. Me lo pregunto yo que tuve un acceso temprano a esos materiales de escritura y sin embargo podía ver que me estaba quedando a medio camino. Pienso ahora en el diálogo que establece este libro con el universo Puig que incluye muchas más firmas que las comentadas (Sosnowski, Pauls, Link, Speranza, Pollarolo, muchas más) y veo que una de las claves de esa diferencia está en una operación que es del orden del lenguaje y tarea de la filología, la de establecer y a un tiempo suspender todas las disposiciones. Esta suspensión es lo que Delfina Cabrera escuchó con oído de traductora. 